\title{
The epidemiology and management of traumatic facial fractures in children seen in a tertiary hospital in Johannesburg, South Africa
}

\begin{abstract}
Introduction

Serious head and facial injuries contribute as one of the leading causes of higher injury severity scores, prolonged hospital stay, mortality and morbidity in young children.
\end{abstract}

Aim

To determine the prevalence of traumatic facial fractures in children under the age of 15 years in Johannesburg, South Africa.

\section{Objectives}

To determine the aetiology, age and gender mostly affected, identify anatomical distribution with associated injuries and to record the management of facial fractures.

\section{Methods}

This was a retrospective study based on data retrieved from admission records.

Results

Of the 4044 admissions, 171 children had facial fractures, a prevalence of $4,2 \%$. Most patients were males. The mean age was $6.45 \pm 3.47$ years.

Author affiliations:

1. Gerhard Fouche: BChD (Stellenbosch/UWC), MSc (Wits), Annex 7 Wilgeheuwel Hospital, Amplifier road, Radiokop, Johannesburg, South Africa.

ORCID Number: 0000-0002-2409-1504

2. Mzubanzi Mabongo: STD, B Dent (MEDUNSA), BDS (Wits), MChD (MFOS) (UWC), Cert. Orofacial Pain, FCFS, Head, Clinical Unit, Department of Oral and Maxillofacial Surgery; University of the Witwatersrand, York Road, Parktown, Level 4, Room 4I09, Johannesburg, South Africa.

Corresponding author: Gerhard Fouche

Annex 7 Wilgeheuwel Hospital, Amplifier road, Radiokop, Johannesburg, South Africa.

Tel: +27 (0)11675 3026

Email: gfouche@gmail.com

Author contributions:

1. Gerhard Fouche: Conception and design of study, acquisition of data, analysis and interpretation of data, drafting of article/critical revision, final approval and guarantor of manuscript - $70 \%$

2. Mzubanzi Mabongo: Conception and design of study, acquisition of data, analysis and interpretation of data, drafting of article/ critical revision, final approval and guarantor of manuscript - $30 \%$

\author{
ACRONYMS \\ MVAs: $\quad$ Motor Vehicle Accidents \\ NOE: Nasal-Orbital-Ethmoidal \\ PVAs: $\quad$ Pedestrian Vehicle Accidents \\ PCC: Road Traffic Accidents
}

The most frequent causes of the 247 facial fractures recorded were pedestrian vehicle accidents (PVAs), motor vehicle accidents (MVAs) and falls. The frontal bone followed by the orbital bone were the most common fracture sites.

Twelve patients showed ophthalmic/globe involvement, 49 had an associated tooth injury, 117 had associated bodily injuries and 435 facial soft tissue injuries (STIs) were detected. One hundred and nine (63.7\%) patients were managed conservatively, while 58 (34.0\%) required surgical intervention.

\section{Conclusion}

There is a statistically significant association between age and the cause of fracture.

\section{Keywords}

Maxillofacial, trauma, fractures, paediatrics, children.

\section{INTRODUCTION}

Serious head and facial injuries are recognized as some of the leading causes of higher injury severity scores, prolonged hospital stay, morbidity and mortality in young children. ${ }^{1-6}$

In some countries head injuries remain the most common cause of mortality in paediatric patients, ${ }^{4,5}$ whilst traumatic dentoalveolar injuries are generally considered as a serious public dental health problem amongst young children. ${ }^{1,4}$ Facial fractures do occur less frequently in children than in adults, ${ }^{7}$ and paediatric patients are more likely to sustain greenstick or incomplete fractures and fractures that are less likely to have multiple communications. ${ }^{7,8}$

Previous retrospective studies of paediatric maxillofacial trauma show a facial fracture prevalence range of $1 \%-14.7 \%$ in children under 16 years of age. ${ }^{1-3,9-13}$ 
This low prevalence of facial fractures in children, compared with adults, is most possibly due to particular anatomic features including the under-developed facial skeleton and para-nasal air sinuses; the craniofacial disproportion in size; the thicker layer of surrounding adipose tissue covering the more elastic, thin cortical bones of the paediatric facial skeleton.

The un-erupted dentition of the mandible and maxilla and the lack of sinus pneumatisation provides additional strength and stability of the jaws. The abundance of cartilage and cancellous bone, low mineralization and underdeveloped cortex, and the more flexible suture lines of the facial bones and indistinct corticomedullary junctions, confer greater intrinsic elasticity and flexibility on the paediatric facial skeleton.

The increased number of fat pads around the upper and lower jaws offer protection. ${ }^{1,3,5,7,8,10-16}$ With advancing age and physiological development, facial growth increases in a forward and downward direction resulting in prominence of the midface and the mandible, which tends to lead to a decrease in the incidence of cranial and frontal bone injuries and a higher incidence of facial trauma (fracture injuries of the midface, mandible and orbit). $5,11,12,15,16$

Although the incidence rates for causes of injury vary from one country to another, studies from across the world suggest that the most frequent causes of facial injuries and fractures in children are falls, road traffic accidents (RTA), sports, social play and violence. . $^{1-3,5,9,10,12,15,16,18-20}$

Child abuse is not an uncommon cause of facial injury. ${ }^{12}$ Many cases of child abuse involve trauma to the mouth, face and head. ${ }^{5}$ Repeated injuries, multiple injury sites and questionable circumstances surrounding the injury should raise suspicion of possible abuse. ${ }^{16}$

Various studies show that as many as 50\%-75\% of cases of child abuse involve trauma to the mouth, face, head and neck. ${ }^{5,13}$ Males are more likely sustain facial fractures than females. ${ }^{1-4,9-14,16-18,20}$

The most commonly affected sites of facial fracture in children are the mandible $2,3,7-9,11,12,15,16,18-20$ dentolaveolar, ${ }^{1,8}$ nasal, $, 2,3,10,16$ and upper facial bones (which include the orbital, frontal and nasal-orbital-ethmoidal (NOE) bones), ${ }^{13}$ with soft tissue swelling being the most commonly associated injury. ${ }^{1,8,20}$

The management of facial fractures in children is different from that in adults because of growth biology, age related facial anatomy, dental follicles and mixed dentition. ${ }^{8}$ Conservative and functional treatment is recommended as the first choice for paediatric fracture, because of the high capacity for fracture remodelling. . $^{70,11,15,16}$

The aim of this study is to determine the prevalence of traumatic facial fractures in children in Johannesburg, South Africa. The objectives of this study are to determine the aetiology of the fractures, the age and gender most common amongst the affected children, to identify the anatomical distribution of the trauma and any associated injuries, and to record the management of facial fractures.

\section{METHODOLOGY}

\section{Study design}

This was a retrospective study based on data retrieved from admission records of a trauma unit of a tertiary hospital, from 2011 to 2015. The list of paediatric patients who were admitted for traumatic injuries from 2011 to 2015 was retrieved from the admission books at trauma casualty. In this study paediatric patients included all patients who were 15 years and younger.

The data collected from the admission records were age, gender, aetiology, site of fracture, associated body injuries and management. Patients were divided into three subgroups of age from 0-5 years, 6-10 years and 11-15 years of age. Patients with soft tissue injuries only, above 15 years of age and adults, were excluded from the study.

Ethical clearance for the study was granted by Human Research Ethics Committee (HREC) of the University of the Witwatersrand, protocol M150833 (Addendum A).

\section{Statistical analysis}

The data was captured into a data collection sheet and then transferred into statistical software (IBM SPSS version $23.0(\mathrm{R})$ ). Results were analysed by descriptive statistics and illustrated by tables and graphs. The Fischer's exact test was used to determine the association between the dependent and the independent variables.

\section{RESULTS}

From the 4044 patient files analysed, 171 (4.2\%) paediatric patients with facial bone fractures were recorded. Figure 1 illustrates the yearly paediatric facial fracture prevalence between 2011 and 2015.

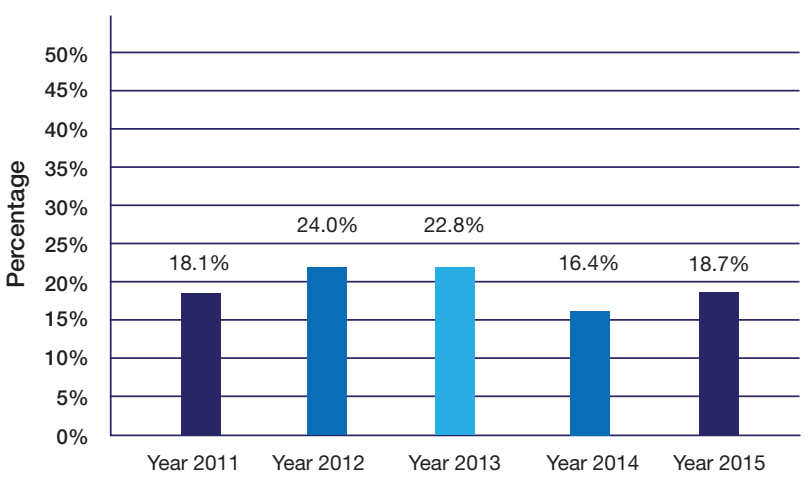

Figure 1. Yearly facial fracture prevalence between 2011 and 2015.

One hundred and nine (63.7\%) children were males and $62(36.3 \%)$ were females. The mean age was $6.45 \pm$ 3.47 years. Seventy children $(41.0 \%)$ were under 5 years of age, 77 (45.0\%) between 6 to 10 years and 24 (14.0\%) between 11 to 15 years of age. Thus, $86.0 \%$ of patients were 10 years of age and younger.

The most common causes of facial fracture were road traffic accidents (PVA and MVA) in 85 patients (49.7\%) and falls in 57 patients (33.3\%). Five (2.9\%) children sustained facial fractures during sporting events. One (0.6\%) child suffered a facial fracture from a bicycle accident. 


\begin{tabular}{|l|r|r|r|r|}
\hline \multicolumn{5}{|c|}{ Table 1. Cause of fracture according to gender of patients } \\
\hline Cause of fracture & \multicolumn{2}{c|}{ Female } & \multicolumn{2}{c|}{ Male } \\
\hline PVA & N & \multicolumn{1}{|c|}{$(\%)$} & N & \multicolumn{1}{l}{$(\%)$} \\
\hline MVA & 21 & 33.9 & 37 & 33.9 \\
\hline Falls & 13 & 21.0 & 14 & 12.8 \\
\hline Bicycle & 18 & 29.0 & 39 & 36.0 \\
\hline Sports & - & - & 1 & 0.9 \\
\hline Violence & - & - & 5 & 4.6 \\
\hline Hit with gate & 7 & 11.3 & 4 & 3.6 \\
\hline Object struck the face & 1 & 1.6 & 7 & 6.4 \\
\hline Not indicated & 1 & 1.6 & - & - \\
\hline Total & 1 & 1.6 & 2 & 1.8 \\
\hline
\end{tabular}

Eleven (6.4\%) children with facial fractures were involved in violence or abuse, whilst 9 (5.3\%) patients were either hit by a gate or other object on the face. The cause was unknown in $3(1.8 \%)$ patients.

The PVA incidence in male and female children were the same, although the MVA incidence rate amongst females was much higher. The facial fracture incidence due to falls was much higher in males. Neither bicycle nor sports injuries were documented amongst females although a $7.6 \%$ higher incidence due to violence were noted in females (Table 1).

A higher incidence and total number of PVAs occurred in children 0-10 years of age, although a greater MVA incidence were noted in children older than 10 years of age. Falls were the major cause of facial fracture in children 0-5 years of age, whilst the incidence of falls in children decreased with age. In this study, a higher facial fracture incidence due to sports and violence were noted in children above 10 years of age (Table 2).

Results also showed that children younger than 5 years of age were approximately 16 times more likely, and those between 6-10 years of age almost 10 times more likely, to sustain a facial fracture injury due to falls, than were children 11-15 years of age. There was a significant association between the cause of fracture and the age of patients $(p<0.05)$.

There were all together 247 facial bone fractures amongst the 171 paediatric patients. Seventy four fractures of the frontal bone were detected, which was the most common site of fracture, followed mostly by the 53 (21.5\%) orbital fractures, and fractures of the maxilla and mandible (Figure 2).

\section{Associated dental injury}

Forty nine $(28.7 \%)$ children with facial fracture had an associated dental injury. The primary or permanent incisors and canines as well as the primary molars were mostly affected. Frequent dental alveolar injuries included mobility, avulsion, displacement, intrusion, fracture or pulpal involvement. Mobility of teeth (in 28 (57.0\%) patients) was the most common associated injury in these 49 patients, followed by avulsion and displacement. Sixteen (33.0\%) children had multiple dental alveolar injuries.

\section{Associated body injuries}

Other bodily injuries noted included injury to the head, to a sinus (which indicated any involvement, opacification or haemosinus) or of any other body part such as the chest, pelvis, limbs and cervical spine. Symptoms such as pain, numbness or nerve damage as well as airway obstruction/involvement were recorded. Of the 171 patients with facial fractures, $43(25.0 \%)$ patients had a single associated bodily injury and 74 (43.0\%) patients presented with multiple bodily injuries, whilst $54(32.0 \%)$ of the patient records did not indicate any of these type of injuries. Of the 278 associated body injuries noted, 86 (30.9\%) were head injuries. Twelve (7\%) patients had associated ophthalmic/globe involvement.

\section{Management}

The 247 facial fractures were managed by 216 various treatments. Four $(2.3 \%)$ of the patient records did not indicate any treatment rendered. One hundred and nine (63.7\%) patients were managed conservatively, while 58 (34.0\%) required surgical intervention which comprised open or closed reduction, debridement, extractions or other facial or head surgery.

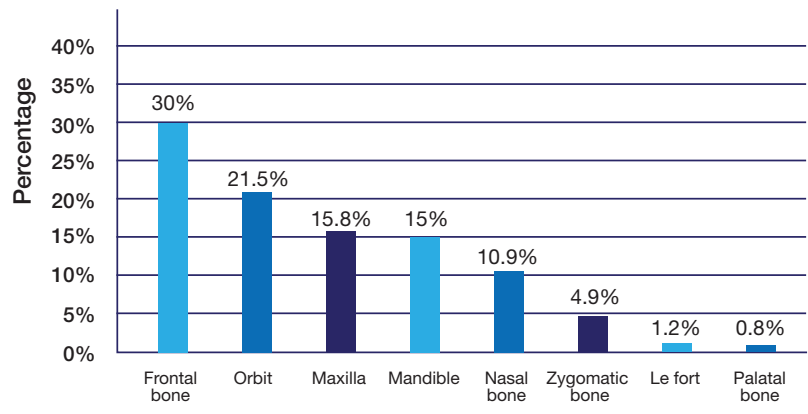

Figure 2. Site of fracture $(\mathrm{N}=247)$.

\begin{tabular}{|c|c|c|c|c|c|c|}
\hline \multirow[b]{2}{*}{ Cause of fracture } & \multicolumn{2}{|c|}{$<1-5$ years } & \multicolumn{2}{|c|}{$6-10$ years } & \multicolumn{2}{|c|}{$11-15$ years } \\
\hline & $\mathbf{N}$ & (\%) & $\mathbf{N}$ & (\%) & $\mathbf{N}$ & (\%) \\
\hline PVA & 22 & 31.4 & 29 & 37.6 & 7 & 29.2 \\
\hline MVA & 8 & 11.4 & 13 & 16.9 & 6 & 25.0 \\
\hline Falls & 31 & 44.3 & 24 & 31.2 & 2 & 8.3 \\
\hline Bicycle & - & - & 1 & 1.3 & - & - \\
\hline Sports & - & - & 2 & 2.6 & 3 & 12.5 \\
\hline Violence & 4 & 5.7 & 3 & 3.9 & 4 & 16.7 \\
\hline Hit with gate & 3 & 4.3 & 3 & 3.9 & 2 & 8.3 \\
\hline Object struck the face & - & - & 1 & 1.3 & - & - \\
\hline Not indicated & 2 & 2.9 & 1 & 1.3 & - & - \\
\hline Total & 70 & 100 & 77 & 100 & 24 & 100 \\
\hline
\end{tabular}




\section{DISCUSSION}

A sample size of 171 patients is small compared with the study of Gassner et al. ${ }^{1}$ who reviewed more than three thousand patients and the 328 patients in a similar study done approximately 20 years ago in the same unit. ${ }^{20}$ However, the current sample size seems to be higher than that of an Indian study of facial fractures which was conducted over a period of ten years. ${ }^{3}$ This difference in sample sizes is thought to be related to the new referral system in South Africa, which demands initial assessment of all patients at primary health facilities, which in turn refer to higher level hospitals.

The low facial fracture prevalence of $4.2 \%$ in this study demonstrates the impact of the system, compared with other studies who reported prevalences between $4.6 \%$ and $19.0 \%^{1,2,5,21-23}$ (Table 3).

In this study road traffic accidents (RTA) were the most common cause of facial fractures, and were classified into PVA and MVA. This finding concurs with some studies which also reported road traffic accident as the most common cause of paediatric facial fractures. $., 11,12,23-25$

Compared with other local studies that separated PVA and MVA, the findings in this study concurred with Lalloo et al. ${ }^{25}$ but differed from Bamjee et al. ${ }^{20}$ who reported MVA to be more common than PVA and secondly indicated violence as the most common cause of facial fractures in children.

The increase of PVA as the cause when compared with Bamjee et al., ${ }^{20}$ which was also done in Johannesburg, may be ascribed to the difference in the upper age limit for paediatric cases (18 years in Bamjee et al. ${ }^{20}$ ), and to changes in the referral system in South Africa.

Anecdotal evidence suggests that political change led to the influx of young people to the cities in search of life opportunities. Lack of recreational facilities, an increase in the informal settlement areas in Johannesburg, driver negligence, insufficient road/pedestrian safety measures, inadequate parental control/supervision or lack of patient education could be an explanation for PVAs being the most common cause of facial fractures in Johannesburg.

Different patterns of aetiology are noted in other international studies. Gassner et al. ${ }^{1}$ showed play injuries fol- lowed by sporting injuries as the most common causes of facial fracture in children, while other studies revealed falls as the most common cause $e^{2,9,18,21,23,25}$ (Table 3). Falls were the second most common cause of facial fractures in the current study, and were more frequent in children under 10 years, especially those $0-5$ years of age.

The very low number of bicycle accidents and sport injuries seems to suggest that most children were from low socioeconomic background and from schools with little sporting activities. This finding differs with Gassner et al. ${ }^{1}$ where play and sporting were the most common causes of maxillofacial injuries.

The incidence of falls tends to decrease with increase in age, and is believed to be associated with development and enhanced control of motoring skills in older children and the lack of defence mechanisms in the very young. ${ }^{6,16}$ It can be said that violence does not seem to lead to admissions to a tertiary hospital even with actual change of aetiological patterns, but the change in the referral system has managed to shift high velocity injuries to the tertiary hospital.

Most facial fractures recorded in this study had occurred in children under 10 years of age. This finding concurs with a report on the profile of head injuries, which also occurred mainly in children under the age of five years. ${ }^{25}$

Other studies found a peak in facial fracture incidence in children between 10-15 years of age, $3,10,12,14,18$ or an increase in incidence with age. $5,11,12,21,23$ Analysis of association between age and aetiology, using Fischer's exact test, showed a statistically significant association between age and cause of fracture with a p-value of 0.01 .

Traffic-related strategies have been found to be effective in reducing pedestrian injuries. These include reduced speed limits in residential suburbs, roundabouts, sidewalks, pedestrian refuge islands, skills training, and legislation such as compulsory seat belt use..$^{25}$

The findings of this study suggest that more still needs to be done to reduce road traffic related accidents in Johannesburg. The local municipalities need to make sure that children do not rely on streets as being the only open spaces for playing.

\begin{tabular}{|c|c|c|c|c|c|c|}
\hline Study & Country & $\begin{array}{l}\text { Study period } \\
\text { (years) }\end{array}$ & Sample & Age limit & $\begin{array}{l}\text { Most common } \\
\text { aetiology }\end{array}$ & $\begin{array}{l}\text { Most common facial } \\
\text { fracture site }\end{array}$ \\
\hline $\begin{array}{l}\text { Gasnner et al. } \\
\text { (1) }\end{array}$ & Austria & 10 & 3385 & 15 & Play & $\begin{array}{l}\text { Maxilla and } \\
\text { mandible }\end{array}$ \\
\hline $\begin{array}{l}\text { Kambalimath et al. } 2013 \\
\text { (3) }\end{array}$ & India & 10 & 112 & 14 & Falls & Mandible \\
\hline $\begin{array}{l}\text { Cavalcanti } \\
\text { (4) }\end{array}$ & Brazil & 4 & 1070 & 17 & Violence & Maxilla \\
\hline $\begin{array}{l}\text { Bamjee et al. } \\
(20)\end{array}$ & RSA & 3,5 & 326 & 18 & Violence & Mandible \\
\hline $\begin{array}{l}\text { Kotecha et al. } 2008 \\
(21)\end{array}$ & UK & 4 & 897 & 16 & Falls & Dentoalveolar \\
\hline This study & RSA & 5 & 171 & 15 & PVA & Frontal bone \\
\hline
\end{tabular}


The 109 (63.7\%) male patients and 62 (36.3\%) females resulted in a female to male ratio of 1:1.75. The male predominance concurs with other studies ${ }^{1-5,9,11,12,14,18-21,23-25}$ and has been attributed to greater and more dangerous physical activities engaged in by boys ${ }^{12}$ and their involvement in outdoor activities and contact sport. ${ }^{21}$ However, there are studies that show equal male to female ratios $^{26,27}$ which could be explained by societies that do not have different chores for males and female.

\section{Anatomical site}

The frontal bone followed by the orbital bone were the most frequent fracture sites in this study. This finding concurs with Van As et al. ${ }^{24}$ who also reported these bones as the two major sites of facial fracture in children. Other studies indicated the mandible and maxilla ${ }^{1,3,5,9,11,12,14,18-20}$ or the nasal bone ${ }^{2,10}$ as the major facial fracture sites.

The variance in the most common sites of fracture may be determined by the cause, age/stage of facial development ${ }^{22}$ and mechanism of injury. ${ }^{1,3,9}$

Although the frontal bone was recorded in this study as sustaining overall the highest number of fractures, the incidence of mandibular bone fracture was greater in children older than ten years of age. This might be related to increase in prominence of the mandible ${ }^{5,11,12,15,17}$ reduction of soft tissue pad and decrease in elasticity of bone with age.

\section{Associated injuries}

Tooth mobility was the most frequent associated tooth injury. Another study revealed the predominance of subluxation. ${ }^{1}$ Of the 435 associated facial soft tissue injuries (STIS) noted, 396 (91.0\%) were extra oral and 9.0\% intraoral which incidence correlates with the $8.0 \%$ intraoral incidence reported by Collao-González et al. ${ }^{2}$

Lacerations, abrasions and soft tissue swellings were the most common soft tissue injuries and a similar finding was reported by Gassner et al. ${ }^{1}$ and Lalloo et al. ${ }^{25}$

This study revealed that 128 (75.0\%) children with facial fractures had multiple associated facial STIs, leading to an incidence greater than other reports..$^{5,9-11}$

The associated bodily injuries amongst 117 (68.0\%) children in this study exceeds the results reported by Collao-González et al. ${ }^{2}$ and Van As et al. ${ }^{24}$ Most children with ophthalmic/globe involvement were under 5 years of age.

\section{Management}

This study revealed that the CT scan is the most requested diagnostic imaging. Van As et al. ${ }^{24}$ also reported use of CT scan as the primary diagnostic imaging in more than $71 \%$ of their patients. Both these studies reported a markedly higher number of frontal and orbital bone fractures, and the proximity of the brain to these bones explains the principal use of CT scans and why neurosurgeons were the most consulted speciality. ${ }^{3}$
In this current study most fractures were managed conservatively, which accords with other studies. ${ }^{19,21}$ The elasticity of bone in children tends to result in minimal displacement, and the greater capacity of children's skeleton for remodelling may explain the success of conservative treatment. . $^{7,11}$

\section{CONCLUSION}

This study revealed a facial fracture prevalence of $4.2 \%$. Male was the predominant gender affected, with road traffic accidents being the most common cause of facial fractures. There is a statistically significant association between age and the cause of fracture.

Associated dental injuries, especially tooth mobility, soft tissue injuries and other bodily injuries were common amongst children with facial fractures. Conservative management is the preferred treatment modality in this age group.

\section{References}

1. Gassner R, Tuli T, Hächl O, Moreira R, Ulmer $H$. Craniomaxillofacial trauma in children: a review of 3385 cases with 6060 injuries in 10 years. J Oral Maxillofacial Surgery. 2004; 62: 399-407.

2. Collao-Gonzalez C, Carrasco-Labra A, Sung-Hsieh $\mathrm{HH}$, Cortés-Araya J. Epidemiology of paediatric facial trauma in Chile: a retrospective study of 7617 cases in 3 years. J of Med Oral Patol Oral Cir Bucal. 2014; 19(2): 99-105.

3. Kambalimath HV, Agarwal SM, Kambalimath DH, Singh $M$, Jain $N$, Michael P. Maxillofacial injuries in children: a 10 year retrospective study. J Maxillofacial Oral Surg. 2013; 12(2): 140-4.

4. Cavalcanti AL. Prevalence and characteristics of injuries to the head and orofacial region in physically abused children and adolescents - a retrospective study in a city of the Northeast of Brazil. Dental Traumatology 2010; 26: 149-53.

5. Imahara SD, Hopper RA, Wang J, Rivara FP, Klein MB. Patterns and outcomes of paediatric facial fractures in the Unites States: A survey of the National Trauma Data Bank. J Am Coll Surg. 2008; 207(5): 710-6.

6. Chang L, Tsai M. Craniofacial injuries from slip, trip and fall accidents of children. The $\mathrm{J}$ of Trauma. 2007; 63(1): 70-4.

7. Smart JM, Low DW, Bartlett SP. The paediatric mandible: management of traumatic injury or fracture. Plast Reconstr Surg. 2005; 116(2): 28-41e.

8. Chao MT, Losee JE. Complications in paediatric facial fractures. Craniomaxillofacial Trauma and Reconstruction 2009; 2(2): 103-12.

9. Kumaraswamy SV, Nanjappa M, Keerthi R, Deora SS. Paediatric injuries in maxillofacial trauma: a 5 year study. J Maxillofacial Oral Surg. 2009; 8(2): 150-3.

10. Kim SH, Lee SH, Cho PD. Analysis of 809 facial bone fractures in a paediatric and adolescent population. $J$ of Arch Plast Surg. 2012; 39: 606-11.

11. Ferreira PC, Amarante JM, Silva PN, et al. Retrospective study of 1251 maxillofacial fractures in children and adolescents. Plast and Reconstr Surg. 2005; 115(6): 1500-8.

12. Ogunlewe MO, James O, Ladeinde AL, Adeyemo WL. Pattern of maxillofacial fractures in Lagos, Nigeria. Int $\mathrm{J}$ of Pediatr Dent. 2006; 16: 358-62.

13. Haug $\mathrm{RH}$, Foss J. Maxillofacial injuries in the paediatric patient. Oral Surg Oral Med Oral Path 2000. 90(2): 126-34.

14. lida S, Matsuya T. Paediatric maxillofacial fractures: their aetiological characters and fracture patterns. J of Craniomaxillofacial Surgery. 2002; 30: 237-41. 
15. Wheeler J, Philips J. Paediatric facial fractures and potential long-term growth disturbances. Craniomaxillofacial Trauma and Reconstruction 2011; 4(1): 43-52.

16. Cole $P$, Kaufman $Y$, Hollier LH. Managing the paediatric facial fracture. Craniomaxillofacial Trauma and Reconstruction 2009; 2(2): 77-83.

17. Oppenheimer AJ, Monson LA, Buchman SR. Paediatric orbital fractures. Craniomaxillofacial Trauma and Reconstruction 2013; 6(1): 9-20.

18. Qudah MA, Bataineh AB. A retrospective study of selected oral and maxillofacial fractures in a group of Jordanian children. J of Oral Surg Oral Med Oral Pathol Oral Radiol and Endod. 2002; 94: 310-4.

19. Karim T, Khan AH, Ahmed SS. Trauma of facial skeleton in children: An Indian perspective. Indian J Surg. 2010; 72 : 232-5.

20. Bamjee Y, Lownie JF, Cleaton-Jones PE, Lownie MA. Maxillofacial injuries in a group of South Africans under 18 years of age. British $J$ of Oral and Maxillofacial Surgery 1996; 34: 298-302.

21. Kotecha S, Scannell J, Monaghan A, Williams RA. A four year retrospective study of 1062 patients presenting with maxillofacial emergencies at a specialist paediatric hospital. British J of Oral and Maxillofacial Surgery 2008; 46: 293-6.

22. Chan YM, Williams S, Davidson LE, Drummond BK. Orofacial and dental trauma of young children in Dunedin, New Zealand. Dental Traumatology 2011; 27: 199-202.

23. Hyder AA, Sugarman DE, Puvanachandra P, et al. Global childhood unintentional injury surveillance in four cities in developing countries: a pilot study. Bull World Health Organ 2009; 87: 345-52.

24. Van As AB, Van Loghem AJ, Biermans BFJ, Douglas TS Wieselthaler N, Naidoo S. Causes and distribution of facial fractures in a group of South African children and the value of computed tomography in their assessment. Int $\mathrm{J}$ of Oral and Maxillofacial Surg. 2006; 35(10): 903-6.

25. Lalloo R, Van As AB. Profile of children with head injuries treated at the trauma unit of Red Cross War Memoria Children's Hospital, 1991 - 2001. SAMJ. 2004; 94(7): 544-5.

26. Fasola AO, Obiechina AE, Arotiba JT. Fractures of the mandible in children, East African Medical Journal 2001; 78: 61-3.

27. Adeyemo WL, Ladeinde AL, Ogunlewe MO, James $O$ Trends and characteristics of oral and maxillofacial injuries in Nigeria: a review of the literature. Head and Face Medicine 2005; 1: 7 . 